\title{
Vitamin D in pregnancy at high latitude in Scotlandt
}

\author{
Paul Haggarty ${ }^{1 *}$, Doris M. Campbell ${ }^{2}$, Susan Knox ${ }^{3}$, Graham W. Horgan ${ }^{4}$, Gwen Hoad $^{1}$, \\ Emma Boulton ${ }^{3}$, Geraldine McNeill ${ }^{5}$ and Alan M. Wallace ${ }^{3}$ \\ ${ }^{1}$ Division of Lifelong Health, Rowett Institute of Nutrition and Health, University of Aberdeen, Greenburn Road, Bucksburn, \\ Aberdeen AB21 9SB, UK \\ ${ }^{2}$ Department of Obstetrics and Gynaecology, Aberdeen University, Aberdeen AB9 2ZD, UK \\ ${ }^{3}$ Department of Clinical Biochemistry, Macewen Building, University of Glasgow, Royal Infirmary, Glasgow G4 OSF, UK \\ ${ }^{4}$ Biomathematics and Statistics Scotland, Rowett Institute of Nutrition and Health, Greenburn Road, Bucksburn, Aberdeen \\ AB21 9SB, UK \\ ${ }^{5}$ Population Health Section, University of Aberdeen, Aberdeen AB25 2ZD, UK
}

(Submitted 13 July 2011 - Final revision received 27 April 2012 - Accepted 30 April 2012 - First published online 24 July 2012)

\section{Abstract}

The aims of the present study were to determine compliance with current advice on vitamin D and to assess the influence of season, dietary intake, supplement use and deprivation on vitamin D status in pregnant mothers and newborns in the north of Scotland where sunlight exposure is low. Pregnant women ( $n$ 1205) and their singleton newborns were studied in the Aberdeen Maternity Hospital (latitude $57^{\circ} \mathrm{N}$ ) between 2000 and 2006. Plasma 25-hydroxyvitamin $\mathrm{D}_{2}$ and 25-hydroxyvitamin $\mathrm{D}_{3}$ were measured at 19 weeks of gestation in mothers and at delivery in newborns. During pregnancy, 21.0 (95\% CI 18.5, 23.5) \% of women took vitamin D supplements. The median intake was $5 \mu \mathrm{g} / \mathrm{d}$ and only $0.6(95 \% \mathrm{CI} 0 \cdot 1,1 \cdot 0) \%$ took the recommended $10 \mu \mathrm{g} / \mathrm{d}$. Supplement use, adjusted for season, dietary intake and deprivation, significantly increased maternal 25 -hydroxyvitamin D (25(OH)D) by $10 \cdot 5(95 \% \mathrm{CI} 5 \cdot 7,15 \cdot 2)$ nmol/1 $(P<0 \cdot 001)$; however, there was no significant effect on cord 25(OH)D $(1 \cdot 4(95 \% \mathrm{CI}-1 \cdot 8,4 \cdot 5) \mathrm{nmol} / \mathrm{l})$. The biggest influence on both maternal and cord $25(\mathrm{OH}) \mathrm{D}$ was season of birth $(P<0 \cdot 001)$. Compared with the least deprived women (top three deciles), the most deprived pregnancies (bottom three deciles) were characterised by a significantly lower seasonally adjusted $25(\mathrm{OH}) \mathrm{D}(-11.6(95 \% \mathrm{CI}-7.5,-15.7) \mathrm{nmol} / 1$ in the mother and $-5.8(95 \% \mathrm{CI}-2 \cdot 3,-9 \cdot 4) \mathrm{nmol} / 1$ in the cord), and a lower level of supplement use (10 (95\% CI 4, 17) $v .23$ (95\% CI 20,26$) \%)$. More should be done to promote vitamin D supplement use in pregnancy but the critical importance of endogenous vitamin D synthesis, and known adaptations of fat metabolism specific to pregnancy, suggest that safe sun advice may be a useful additional strategy, even at high latitude.

\section{Key words: Pregnancy: Supplements: Latitude: Vitamin D}

Pregnant and breast-feeding women in the UK are currently advised to take $10 \mu \mathrm{g}$ of vitamin D daily in supplement form in order to protect against vitamin D deficiency ${ }^{(1-3)}$. Some have argued that higher intakes may be necessary ${ }^{(4,5)}$, while others such as the National Institute for Clinical Excellence have questioned the evidence base for these recommendations $^{(5,6)}$. The Institute of Medicine recently set a RDA for pregnancy and lactation of $15 \mu \mathrm{g} / \mathrm{d}$ for the USA and Canada ${ }^{(7)}$. The UK Scientific Advisory Committee on Nutrition is currently undertaking a review of vitamin $\mathrm{D}$ requirements and recommendations. Concerns have been raised that even the current recommendations may be being overlooked by health professionals and the general public ${ }^{(3)}$.
Vitamin D can only be considered as conditionally essential in the diet, as it can be synthesised by skin exposed to solar radiation of the appropriate wavelength. Indeed, it is an assumption in current UK recommendations that most people obtain the majority of their vitamin $\mathrm{D}$ by exposure of skin to sunlight ${ }^{(1-3)}$. During winter months in the UK, UV sunlight exposure of the required wavelength is not sufficient to support vitamin D synthesis and the duration of this fallow period increases with increasing latitude ${ }^{(3,7-9)}$. The critical importance of latitude and climate on sunlight exposure and vitamin D synthesis has led to concern in Scotland over the vitamin D status of the population in general and pregnant women in particular. A further concern for Scotland is the

Abbreviation: 25(OH)D, 25-hydroxyvitamin D.

*Corresponding author: Professor P. Haggarty, fax + 441224 716622, email p.haggarty@abdn.ac.uk

†The paper is dedicated to Professor A. Mike Wallace who sadly died during the preparation of the manuscript. 
higher level of socio-economic deprivation compared with the rest of the UK, as deprivation is itself associated with poor vitamin D status $^{(10,11)}$.

There is currently no national information on the vitamin D status of pregnant women ${ }^{(3)}$ and a notable absence of data at higher latitudes in the UK where the dietary need is likely to be greatest. The aims of the present study were to determine vitamin D status in mothers and newborns (cord blood) in a large population in the north-east of Scotland (latitude $57^{\circ} \mathrm{N}$ ). We evaluated the influence of season, vitamin D intake from the diet and supplements, compliance with current advice on supplement use, and the modulating effect of deprivation.

\section{Materials and methods}

We carried out a prospective cohort study of pregnancies in Aberdeen, Scotland (latitude $57^{\circ} \mathrm{N}$ ) between 2000 and 2006. The present study was conducted according to the guidelines laid down in the Declaration of Helsinki and all procedures involving human subjects/patients were approved by the Grampian Research Ethics Committee. Written informed consent was obtained from all subjects. Eligible women were enrolled sequentially at the Aberdeen Maternity Hospital. Information on each pregnancy was abstracted from the Aberdeen Maternity and Neonatal Databank and the data anonymised before linking to the dietary and laboratory data. Women who were diabetic or carrying multiple pregnancies were excluded ${ }^{(12)}$. The number of non-Caucasian women in the cohort was small (3\% of the study population), and these were analysed separately. Mothers provided a blood sample at approximately 19 weeks of gestation and cord blood samples were collected at delivery. Plasma concentrations of 25-hydroxyvitamin D (25(OH)D) were determined by liquid chromatography-tandem MS (LC-MS/MS) after solid-phase extraction $^{(13)}$. There are two main forms of vitamin $\mathrm{D}: \mathrm{D}_{3}$ is synthesised in the skin and may also be derived from the diet; $D_{2}$ is derived solely from the diet and supplements may contain either form. The method used here to detect plasma 25(OH)D (LC-MS/MS) is able to distinguish between these forms. The lower limit of quantification was $4 \mathrm{nmol} / 1$ for 25 -hydroxyvitamin $\mathrm{D}_{3}$ and $7.5 \mathrm{nmol} / 1$ for 25-hydroxyvitamin $\mathrm{D}_{2}$. The main concern here was low vitamin D status; therefore, in order not to overestimate this, plasma values below $4 \mathrm{nmol} / 1$ were coded as $3.9999 \mathrm{nmol} / 1$ in the numerical analyses. The distribution of values in the population also suggests that a value close to the cut-off is more likely to be correct than the one closer to zero. Within- and between-assay variability was below $10 \%$ over the concentration range of $22.5-120 \mathrm{nmol} / 1$ for 25 -hydroxyvitamin $\mathrm{D}_{3}$ and $17 \cdot 5-70 \mathrm{nmol} / 1$ for 25 -hydroxyvitamin $\mathrm{D}_{2}$. The calibration was linear up to $2500 \mathrm{nmol} / \mathrm{l}$ ( $r$ 0.99). Recoveries ranged between 89 and $104 \%$ for both metabolites.

Nutrient intake was determined by a self-administered FFQ developed for use in Scottish populations ${ }^{(14)}$ and designed to provide an estimate of habitual diet. The questionnaire was provided to participants at recruitment and returned by the participants on completion later in pregnancy. The energy-adjusted vitamin D intake from natural foods was calculated using the UK National Nutrient Databank (based on McCance \& Widdowson's The Composition of Foods - 5th edition - and related supplementary volumes). The questionnaire included questions relating to the use of food supplements: type/brand; amount per d; timing and duration of consumption in relation to the stage of pregnancy (periconceptual, up to 12 weeks of pregnancy and after 12 weeks). A database of the composition of over 300 different supplement products was developed 'in house' to estimate intake from these sources. The nutrient content of the supplements was as recorded by the manufacturer on the product and therefore does not take into account 'overage' (excess to allow for losses during storage) or other variations due to factors such as shelf life. There is a trend towards increasing use of synthetic vitamin $\mathrm{D}_{3}$ in supplements but those consumed in the present study contained vitamin $\mathrm{D}_{2}$. The study group was generally representative of singleton pregnancies in Aberdeen with respect to a range of indicators (social class, maternal weight, height, pregnancy complications, birth weight, birth outcome and baby health) ${ }^{(15)}$.

\section{Statistical analysis}

Statistical analysis was carried out using STATA/SE version 11 (Stata Corporation) and Genstat (VSN International). The primary response variable was the log-transformed plasma vitamin $\mathrm{D}$ in the mother and cord blood (to ensure approximate normal distributions). We were interested in whether the time-of-year effect followed the natural approximately sinusoidal pattern in the amount and strength of solar radiation, so sinusoidal variation was assessed by taking the cosine and sine of the month (1-12) the maternal sample was taken or the month of birth, scaled to the range $(0,2 \pi)$. The sine term (phase) was not significant in any of the models and was dropped from the analysis. For results grouped by season, the following commonly accepted categories were used: winter (December, January, February); spring (March, April, May); summer (June, July, August); autumn (September, October, November). Vitamin D supplement use was coded as 1 (consumption recorded at any stage) or 0 (no consumption recorded at any stage). Separate analysis of supplement use (any $v$. none) and the reported intake $(\mu \mathrm{g} / \mathrm{d})$ was carried out by the stage of pregnancy. Deprivation was assessed using the Scottish Index of Multiple Deprivation $2004^{(16)}$ This metric provides a comprehensive picture of multiple deprivation by area (UK postcode) based on thirty-one indicators which describe various aspects of deprivation including current income, employment, housing, health, education, skills and training, and geographic access to services and telecommunications. The deciles are based on the whole population. Because the proportion of women in the most deprived deciles was relatively small, pregnancies were grouped into three categories (deciles 1-3, 4-7 and 8-10). Smoking habits were also recorded, but these had no independent effect on $25(\mathrm{OH}) \mathrm{D}$ concentrations. Factors potentially affecting vitamin D status were first examined individually by ANOVA if discrete or by regression if continuous, thereby 
ignoring the potential confounding effect of other factors. They were then examined in a full, single-stratum linear model incorporating the effects of all factors, so that the effect uniquely attributable to each factor could also be estimated and tested. Multiple linear regression was used for continuous dependent variables and logistic regression for binary outcomes.

\section{Results}

We studied 1205 pregnant women and their singleton newborns. The number of non-Caucasian (African, Asian and Indian) mothers recruited to the study was small ( $n$ 42, 3\% of the study population). Plasma $25(\mathrm{OH}) \mathrm{D}$ was compared with non-Caucasian pregnancies but no further analysis was undertaken as low power leading to non-significant effects could be misleading. For non-Caucasian mothers, the characteristics were age at delivery (31.5 (SD 5.0) years), height $(160.7(\mathrm{sD} 6 \cdot 2) \mathrm{cm})$, gestational age at delivery $(38.8(\mathrm{SD} 1.8)$ weeks) and $43 \%$ primiparous. The birth weight was 3183 (SD 563) $\mathrm{g}$ in non-Caucasian pregnancies and $57 \%$ of babies were female. The characteristics of Caucasian pregnancies are shown in Table 1.

There was some variation in the numbers sampled in each season: 25, 34, 25 and 16\% for maternal blood and 18, 19, 28 and $35 \%$ for cord blood in winter, spring, summer and autumn, respectively. However, deviation from equal sampling was sufficiently small that adjustment for this made no significant difference to any of the summary statistics.

The mean dietary intake of vitamin D in pregnancy was 3.7 (95\% CI 3.6, 3.8) $\mu \mathrm{g} / \mathrm{d}$ and 21.0 (95\% CI 18.5, 23.5) \% of women reported using vitamin D-containing supplements at some point in pregnancy (Table 2). There was no evidence of seasonal variation in the intake of vitamin $\mathrm{D}$ from the diet or the proportion of mothers taking supplements. Information on the timing of supplement use was also collected: periconceptual; up to 12 weeks of pregnancy; after 12 weeks. The percentage of taking supplements in these three periods was 10.7 (95\% CI 8.8, 12.5), 16.4 (95\% CI 14.1, 18.6) and 13.7 (95\% CI $11.6,15.8) \%$, respectively. The corresponding percentages for those taking the recommended intake of $10 \mu \mathrm{g} / \mathrm{d}$ or more were 1.3 (95\% CI $0.6,1.9), 1.6$ (95\% CI 0.9 , $2 \cdot 4)$ and $0.6(95 \%$ CI $0 \cdot 1,1 \cdot 0) \%$

We were unable to detect the $\mathrm{D}_{2}$ form of $25(\mathrm{OH}) \mathrm{D}$ in any of the maternal or cord samples. The geometric mean 25(OH)D concentration in maternal plasma, sampled at 19 weeks of gestation, was $40 \cdot 1(95 \%$ CI $38.5,41 \cdot 8) \mathrm{nmol} / 1$ with $21 \cdot 5$

Table 1. Subject characteristics

(Mean values and standard deviations)

\begin{tabular}{|c|c|c|}
\hline & Mean & SD \\
\hline Age at delivery (years) & $30 \cdot 7$ & $5 \cdot 3$ \\
\hline Height $(\mathrm{cm})$ & 164 & 7 \\
\hline Primiparous (\%) & \multicolumn{2}{|c|}{50} \\
\hline Baby sex (\% female) & \multicolumn{2}{|c|}{49} \\
\hline Gestational age at delivery (weeks) & $39 \cdot 3$ & $5 \cdot 3$ \\
\hline Birth weight $(\mathrm{g})$ & 3449 & 568 \\
\hline
\end{tabular}

(95\% CI 19.1, 23.9) \% of women exhibiting vitamin D levels below $25 \mathrm{nmol} / 1$, commonly used as the threshold for deficiency. The geometric mean concentration in cord blood at delivery was $46 \%$ lower than that in the mother at 19 weeks of gestation and 50 (95\% CI 46, 54)\% of cord blood was below the $25 \mathrm{nmol} / 1$ cut-off. In $3 \%$ of the maternal samples and $13 \%$ of the fetal samples, plasma $25(\mathrm{OH}) \mathrm{D}$ was below the detection limit of the assay $(4 \mathrm{nmol} / \mathrm{l})$. The highest $25(\mathrm{OH}) \mathrm{D}$ values were seen in summer $(53 \mathrm{nmol} / \mathrm{l})$. The lowest $25(\mathrm{OH}) \mathrm{D}$ concentrations $(34 \mathrm{nmol} / \mathrm{l})$, and the greatest proportion of cases below the $25 \mathrm{nmol} / 1$ cut-off, were observed in autumn (27\%) and winter (28\%) when sunlight exposure is lowest.

Univariate regression analysis of the effect of the factors thought to influence vitamin D status showed significant effects on maternal $25(\mathrm{OH}) \mathrm{D}$ of time of year (cosine coefficient $-0.252 ; 95 \%$ CI $-0.308,-0.197 ; P<0.001)$, intake from the diet (coefficient $0.022 ; 95 \%$ CI $0.002,0.041$; $P=0 \cdot 030$ ), supplement use (coefficient $0 \cdot 268 ; 95 \%$ CI $0 \cdot 166$, $0.371 ; P<0.001$ ) and deprivation (coefficient $-0.151 ; 95 \%$ CI $-0.213,-0.088 ; P<0.001)$. There was no significant effect of body weight or BMI at booking. The corresponding univariate analysis in cord plasma $25(\mathrm{OH}) \mathrm{D}$ also showed a significant effect of time of year (cosine coefficient $-0.519 ; 95 \%$ CI $-0.611,-0.427 ; P<0.001$ ) and deprivation (coefficient $-0.14995 \% \mathrm{CI}-0.254,-0.044 ; P=0 \cdot 005)$. Again, there was no significant effect of body weight or BMI at booking. In contrast to the maternal plasma results, neither the dietary intake of vitamin D or supplement use by the mother had a significant effect on the newborn plasma 25(OH)D. Maternal plasma $25(\mathrm{OH}) \mathrm{D}$ was an important determinant of the $25(\mathrm{OH}) \mathrm{D}$ of the newborn (coefficient $0 \cdot 376 ; 95 \%$ CI $0 \cdot 284$, $0.468 ; P<0.001)$ despite these being sampled in different seasons.

Multiple regression analysis of the factors influencing plasma $25(\mathrm{OH}) \mathrm{D}$ in the mother and newborn is summarised in Table 3. The maternal model included the influence of time of year (cosine fit), vitamin D intake from the diet, the use of vitamin D-containing supplements, and the level of deprivation. The same parameters were fitted to cord $25(\mathrm{OH}) \mathrm{D}$, but this model also included maternal plasma 25(OH)D.

Most of the variation in cord plasma 25(OH)D was accounted for by time of year, following a smooth sinusoidal path (Fig. 1). The newborn plasma 25(OH)D curve minima, adjusted for all the parameters in the regression model, corresponded to the solar nadir in December to January $(11.7 ; 95 \%$ CI $10 \cdot 4,13 \cdot 0 \mathrm{nmol} / \mathrm{l})$. The curve maxima corresponded to the zenith in June to July (38.5; $95 \%$ CI $34.7,42.3 \mathrm{nmol} / \mathrm{l})$. The maximum-to-minimum difference in the newborn was $26 \cdot 8$ (95\% CI 22.4, 31.3) nmol/l. There was also a strong annual variation in maternal $25(\mathrm{OH}) \mathrm{D}$ status (Fig. 1). The fully adjusted maternal plasma 25(OH)D curve minima in December to January was $31.3(95 \%$ CI $29 \cdot 1,33.6) \mathrm{nmol} / 1$ and the maxima in June to July was $51 \cdot 7$ (95\% CI 48.3, 55.2) nmol/l. The maximum-to-minimum difference in maternal plasma was $20.4(95 \%$ CI $15 \cdot 7,25 \cdot 1) \mathrm{nmol} / \mathrm{l}$. The cosine fit was again highly significant, though it can be seen from the 
figure that maternal variation in plasma $25(\mathrm{OH}) \mathrm{D}$ throughout the year was not a simple sinusoid. Maternal plasma $25(\mathrm{OH}) \mathrm{D}$ at 19 weeks of gestation was better described by a step change between two levels; a constant background level for 8 months of the year (September to April) with a step up to the higher value during the four summer months (May to August). Inclusion of a variable coding for this step change ( 0 for September to April and 1 for May to August) was highly significant in the maternal regression model $(P<0 \cdot 001)$. It also better described the annual maternal $25(\mathrm{OH}) \mathrm{D}$ variation than the cosine fit as the cosine term was not significant when the step-change variable was included in the regression model. The opposite was true in the cord blood model: when the cosine term and the step-change variable were both included in the model, the former remained highly significant $(P<0 \cdot 001)$ while the latter was not significant.

Dietary intake of vitamin $\mathrm{D}$ had no effect on maternal plasma $25(\mathrm{OH}) \mathrm{D}$ but the use of vitamin D-containing supplements had a significant effect on maternal plasma 25(OH)D. Supplement use, adjusted for time of year, dietary vitamin $\mathrm{D}$ intake and deprivation, was associated with a significant $(P<0 \cdot 001)$ increase in maternal plasma $25(\mathrm{OH}) \mathrm{D}$ of $10 \cdot 5(95 \%$ CI $5 \cdot 7,15 \cdot 2) \mathrm{nmol} / \mathrm{l}$. Neither the maternal dietary intake of vitamin D nor the use of vitamin D-containing supplements had any significant effect on the more important cord plasma $25(\mathrm{OH}) \mathrm{D}$ with or without adjustment for maternal plasma $25(\mathrm{OH}) \mathrm{D}(1.4(95 \% \mathrm{CI}-1.8,4.5)$ and $-1.5(95 \% \mathrm{CI}$ $-5 \cdot 3,2 \cdot 3) \mathrm{nmol} / \mathrm{l}$ respectively). After time of year, the largest influence on cord blood $25(\mathrm{OH}) \mathrm{D}$ was maternal plasma $25(\mathrm{OH}) \mathrm{D}$ followed by level of deprivation. For the purposes of this analysis, the Scottish Index of Multiple Deprivation was analysed in three groups but the relationships remained significant in regression models using Scottish Index of Multiple Deprivation quintiles. Maternal plasma $25(\mathrm{OH}) \mathrm{D}$ is itself determined by other factors in the model and adjustment for maternal plasma 25(OH)D partially removes the effect of these. Excluding maternal $25(\mathrm{OH}) \mathrm{D}$ from the cord blood regression model resulted in the same basic outcomes, though the effect of deprivation was more significant $(P<0.0077)$.

Deprivation was also significantly linked to the dietary intake of vitamin D $(P=0 \cdot 004)$, supplement use $(P=0 \cdot 001)$, the proportion of mothers $(P<0.001)$ and newborns $(P=0.027)$ with plasma 25(OH)D below $25 \mathrm{nmol} / 1$ (Fig. 2). Supplement use in the most deprived women (bottom three deciles: 10; 95\% CI 4, 17\%) was less than half that in the top three deciles (23; 95\% CI 20, 26\%). Compared with the least deprived women, the most deprived pregnancies were characterised by a lower time of year-adjusted $25(\mathrm{OH}) \mathrm{D}$ $(-11.6(95 \% \mathrm{CI}-7.5,-15.7) \mathrm{nmol} / \mathrm{l}$ in the mother and $-5.8(95 \% \mathrm{CI}-2.3,-9.4) \mathrm{nmol} / \mathrm{l}$ in the cord). There were no significant relationships between maternal or cord plasma $25(\mathrm{OH}) \mathrm{D}$ and birth weight or standardised birth weight, with or without adjustment for the level of deprivation.

Compared with Caucasians, plasma $25(\mathrm{OH}) \mathrm{D}$ in non-Caucasians was significantly lower in the maternal $(-23.1 \mathrm{nmol} / \mathrm{l}$; $P<0.001)$ and cord $(-10.9 \mathrm{nmol} / 1 ; P<0.001)$ blood. 
Table 3. Factors affecting maternal ${ }^{*}$ and cord 25-hydroxyvitamin $\mathrm{D}(25(\mathrm{OH}) \mathrm{D})$ concentrations $\dagger$ (Coefficients and $95 \%$ confidence intervals)

\begin{tabular}{|c|c|c|c|c|c|c|}
\hline & \multicolumn{3}{|c|}{ Maternal plasma 25(OH)D (log nmol/l)‡ } & \multicolumn{3}{|c|}{ Cord plasma 25(OH)D (log nmol//)§ } \\
\hline & Coefficient & $95 \% \mathrm{Cl}$ & $P$ & Coefficient & $95 \% \mathrm{Cl}$ & $P$ \\
\hline Seasonal variation (cosine fit) & -0.251 & $-0.307,-0.195$ & $<0.001$ & -0.597 & $-0.684,-0.509$ & $<0.00$ \\
\hline Dietary intake of vitamin $D(\mu \mathrm{g} / \mathrm{d})$ & 0.014 & $-0.004,0.033$ & 0.131 & 0.013 & $-0.012,0.039$ & 0.307 \\
\hline Use of vitamin D supplements (any $v$. none) & 0.238 & $0.137,0.338$ & $<0.001$ & -0.062 & $-0.210,0.086$ & 0.405 \\
\hline Deprivation (SIMD deciles in three categories) & -0.105 & $-0.169,-0.042$ & 0.001 & -0.095 & $-0.186,-0.004$ & 0.040 \\
\hline Maternal plasma $25(\mathrm{OH}) \mathrm{D}(\mathrm{nmol} / \mathrm{l})$ & - & - & - & 0.497 & $0.408,0.586$ & $<0.001$ \\
\hline
\end{tabular}

SIMD, Scottish Index of Multiple Deprivation.

*Maternal blood was sampled at 19 weeks of gestation.

† Excluding non-Caucasian mothers.

$¥$ The effect on maternal plasma log $25(\mathrm{OH}) \mathrm{D}$ of time of year, dietary intake, use of vitamin D-containing supplements and level of deprivation was determined by multiple regression (model adjusted $\left.r^{2} 10 \%\right)$. Sinusoidal seasonal variation was assessed by taking the cosine of month the maternal sample was taken, scaled to the range $(0,2 \pi)$. Use of vitamin D-containing supplements was recorded as yes or no. Deprivation group was based on the SIMD 2004 with population deciles grouped into three categories: deciles $1-3,4-7$ and $8-10$.

$\S$ The cord plasma log 25(OH)D model included the additional variable of maternal plasma 25(OH)D (model adjusted $r^{2} 35 \%$ ). Sinusoidal seasonal variation in cord blood was assessed by taking the cosine of the month of birth.

\section{Discussion}

Women in the UK are advised to take $10 \mu \mathrm{g}$ of vitamin D daily in supplement form throughout pregnancy in order to avoid deficiency $^{(1-3)}$. Only $21 \%$ of the women in the present study population in the north of Scotland reported taking vitamin D supplements compared with $15 \%$ in pregnant women in the south of England (Southampton) ${ }^{(17)}$. However, the true picture is worse than even this low percentage suggests. Only about $1 \%$ of women took the recommended $10 \mu \mathrm{g} / \mathrm{d}$ or more at any stage in pregnancy (the value was 3\% in Southampton $^{(17)}$ ), with the great majority taking $5 \mu \mathrm{g} / \mathrm{d}$ (the most commonly available dosage). The use of supplements was associated with a higher maternal circulating concentration of $25(\mathrm{OH}) \mathrm{D}$, though the effect was small. Supplement use is confounded by a number of factors such as deprivation, and full adjustment showed that supplement use increased maternal plasma $25(\mathrm{OH}) \mathrm{D}$ by $10.5 \mathrm{nmol} / 1$. However, there was no detectable effect (adjusted or unadjusted) on the more important cord plasma $25(\mathrm{OH}) \mathrm{D}$ at birth. This reinforces concerns over the effectiveness of public health policy in promoting supplement use ${ }^{(3)}$, though there was no evidence that compliance in the north of Scotland was significantly worse than elsewhere in the $\mathrm{UK}^{(17)}$. The correlation between the intake of vitamin D from the diet and plasma 25(OH)D was weak in the mother and absent in the newborn, and there was no evidence that the dietary intake of vitamin D was low compared with non-pregnant women in the rest of the $\mathrm{UK}^{(9,10)}$. The fact that the $\mathrm{D}_{2}$ form was undetectable in any of the maternal or cord blood analysed reinforces the conclusion that supplements and the diet made a minor contribution to vitamin D status in these pregnancies.

The plasma $25(\mathrm{OH}) \mathrm{D}$ value observed in these pregnant women in the north of Scotland (latitude $57^{\circ} 12^{\prime} \mathrm{N}$ ) was about $10 \mathrm{nmol} / 1$ lower than that observed in pregnant women in the south of England (latitude $\left.50^{\circ} 57^{\prime} \mathrm{N}\right)^{(17)}$. In the Southampton study, $18 \%$ of pregnant women were classed as deficient based on a cut-off of $27.5 \mathrm{nmol} / 1$. Application of the same cutoff to Aberdeen pregnancies gave a deficiency prevalence of
$29 \%$ (21\% using the more commonly cited deficiency cut-off of $25 \mathrm{nmol} / \mathrm{l})$. Sampling in the Southampton study was carried out later in pregnancy, but there is little evidence for a consistent change in plasma 25(OH)D levels across pregnancy ${ }^{(18-20)}$, and a recent review suggested that plasma 25(OH)D levels do not change unless intake or synthesis changes ${ }^{(21)}$. There are published values for $25(\mathrm{OH}) \mathrm{D}$ deficiency in pregnant women in Northern Ireland ${ }^{(22)}$ but comparison with that cohort is difficult as the sampling was confounded by season.

There was a strong seasonal variation in vitamin D levels in the mother and newborn. Cord blood vitamin D followed a classic sinusoidal pattern which mirrors the annual variation in UVB exposure at this latitude. Maternal blood was not sampled at delivery but we would expect the seasonal variation in cord $25(\mathrm{OH}) \mathrm{D}$ to reflect maternal plasma at this stage of pregnancy. Maternal plasma, sampled in mid-gestation, also demonstrated a strong seasonal variation, but there was a significant deviation from the sinusoidal pattern at this stage of pregnancy. For the 8 months of the year when UVB exposure is lowest, there was little variation in maternal 25(OH)D but a step change to a higher level in May and down again in September. Winter and spring values are generally low in the $\mathrm{UK}^{(9,17)}$, but the rapid postsummer drop in plasma 25(OH)D observed here at high latitude in mid-gestation would be consistent with a greater rate of vitamin $\mathrm{D}$ sequestration into adipose tissue resulting from the high rate of maternal fat deposition at this stage of pregnancy; approximately $160 \mathrm{~g} /$ week $^{(23)}$.

The absence of a significant response in cord 25(OH)D to vitamin D supplement use in these women contrasts with the findings of a large $(n>1000)$ intervention study in women from a similar ethnic background and latitude (Edinburgh, Scotland; latitude $\left.55^{\circ} 57^{\prime} \mathrm{N}\right)^{(24)}$. Supplementation with vitamin $\mathrm{D}$ at the recommended level of $10 \mu \mathrm{g} / \mathrm{d}$ from week 12 of gestation to term increased maternal plasma $25(\mathrm{OH}) \mathrm{D}$ by about $10 \mathrm{nmol} / 1$ at delivery, cord plasma by $8 \mathrm{nmol} / 1$, and neonate plasma at $6 \mathrm{~d}$ post-partum by $14 \mathrm{nmol} / \mathrm{l}$. If all the women in the present Aberdeen study who did not consume supplements followed current advice, and achieved the effect 

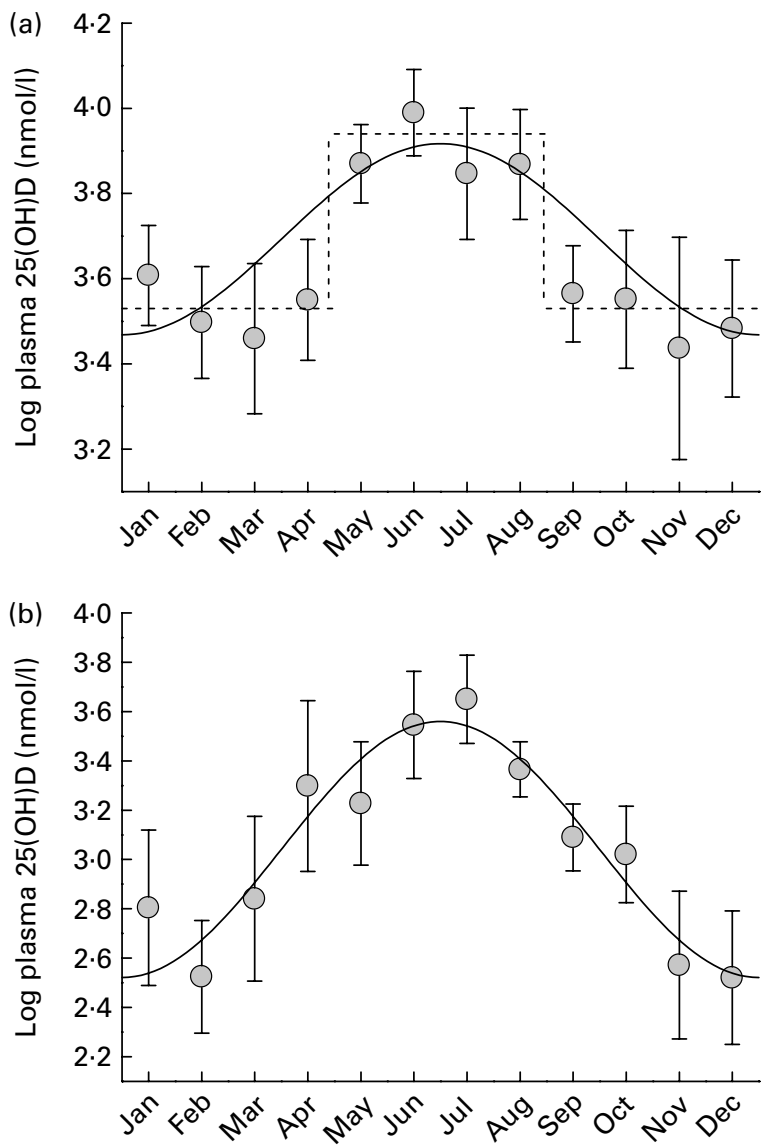

Fig. 1. Seasonal variation in log-transformed 25-hydroxyvitamin $D(25(\mathrm{OH}) \mathrm{D})$ in maternal blood at 19 weeks of gestation (a) and in cord blood at delivery (b). The maternal data are shown with the cosine fitted curve $(-)$ together with the step change (---) between two distinct concentrations of maternal $25(\mathrm{OH}) \mathrm{D}$. The newborn $\log 25(\mathrm{OH}) \mathrm{D}$ concentration is shown with the cosine fitted curve (-). Values are means at each month, with $95 \% \mathrm{Cl}$ represented by vertical bars.

observed in the Cockburn trial, the prevalence of deficiency in the north of Scotland would be reduced by two-thirds (from 23 to $8 \%$ ) and the observed difference in plasma $25(\mathrm{OH}) \mathrm{D}$ between the north of Scotland and the south of England ${ }^{(17)}$ would be abolished.

The Cockburn trial ${ }^{(24)}$ shows that supplement use at the recommended levels works, albeit with relatively modest effects on status. Therefore efforts to improve the uptake of current vitamin $\mathrm{D}$ advice in pregnancy should continue but a number of factors are likely to work against the effectiveness of this strategy. The need to consume $10 \mu \mathrm{g}$ of supplemental vitamin D every day throughout pregnancy is demanding and the way the supplements were actually consumed in practice here was insufficient to influence the newborn 25(OH)D in spite of there being a detectable effect on maternal status. Also, even if every pregnant woman in the present study followed the advice fully, about $8 \%$ would still be deficient in vitamin D. Furthermore, women most likely to benefit from vitamin D supplement use are typically the most disadvantaged in the society who are also less likely to follow the advice on supplement use in pregnancy ${ }^{(12)}$. This is borne out by the data here for vitamin D supplement use. Non-pregnant women from deprived households have lower intakes of vitamin $\mathrm{D}^{(10)}$ and lower concentrations of plasma $25(\mathrm{OH}) \mathrm{D}^{(11)}$, and the data presented here suggest that this also holds true for pregnancy. However, they appear to have a further disadvantage with respect to vitamin D. Even after adjustment for dietary intake and supplement use, there remains a residual effect of deprivation on $25(\mathrm{OH}) \mathrm{D}$ concentrations in the mother and newborn reflecting cutaneous synthesis. The prevalence of deficiency in non-pregnant women in Aberdeen was much reduced if they reported a recent holiday abroad ${ }^{(25)}$. Financial constraints clearly limit opportunities to holiday abroad in countries with more intense sunlight but, even within the UK, there is a strong social gradient in the frequency of use of green spaces ${ }^{(26)}$, with likely knock-on effects on exposure to sunlight.
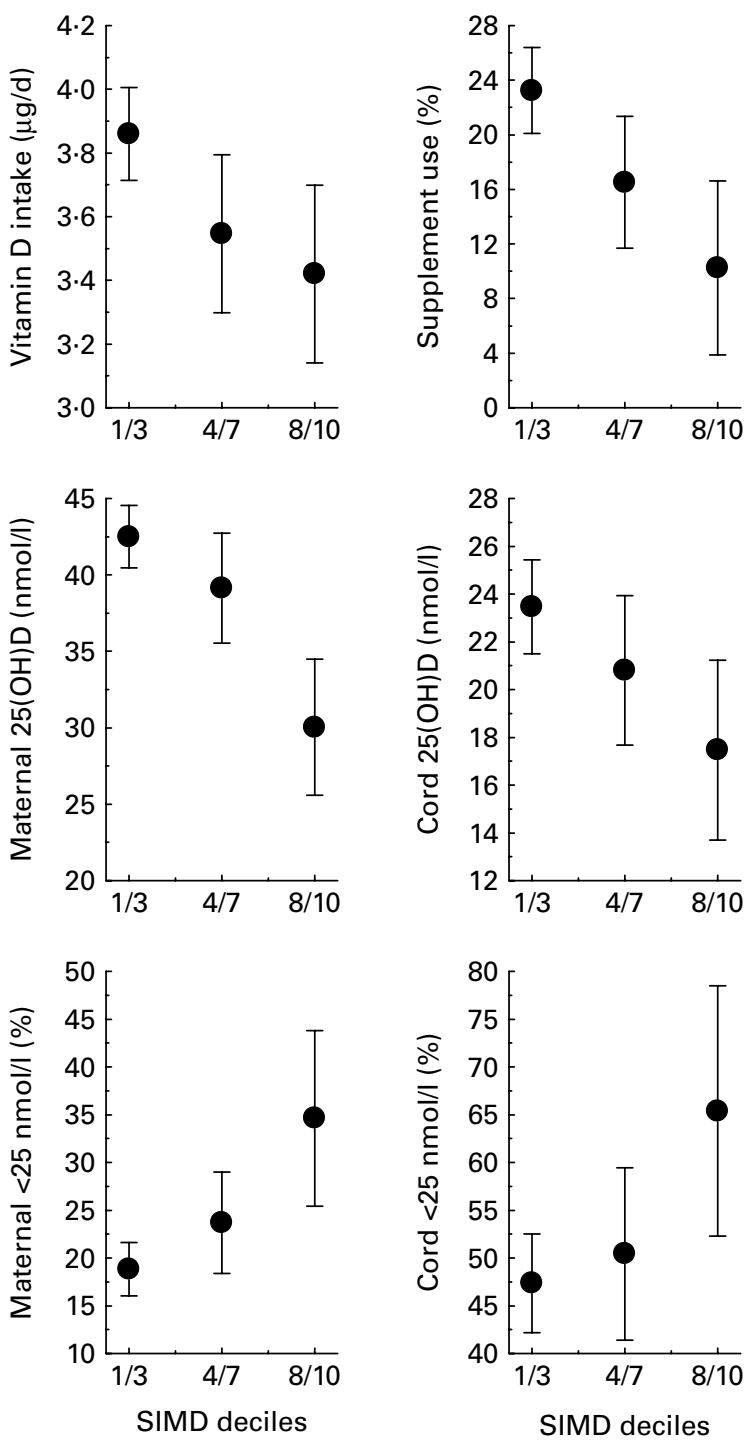

Fig. 2. Deprivation category and dietary intake of vitamin $D$, frequency of supplement use, and maternal and cord plasma 25-hydroxyvitamin D $(25(\mathrm{OH}) \mathrm{D})$. Values are means, with $95 \% \mathrm{Cl}$ represented by vertical bars. Deprivation category was based on the Scottish Index of Multiple Deprivation (SIMD), with population deciles grouped into deciles 1-3, 4-7 and 8-10. Maternal blood was sampled at 19 weeks of gestation. 
Multiple lines of evidence point to the overwhelming importance of sunlight in determining vitamin $\mathrm{D}$ status in pregnancy, even in the north of Scotland. At high latitude, the period during which cutaneous synthesis is possible may be very limited; therefore, efforts to improve vitamin D status through sunlight exposure critically depend on the effectiveness of mechanisms to store vitamin D synthesised in some parts of the year and mobilise it in others. Storage of vitamin D in adipose tissue is thought to be more efficient for endogenously synthesised rather than ingested vitamin $\mathrm{D}^{(27,28)}$. Body fatness increases the sequestration of vitamin $\mathrm{D}$ into adipose tissue and significant fat mobilisation is required to maximise the availability of stored vitamin $\mathrm{D}^{(7,29-31)}$. Seasonal cycles of fat storage in summer, when vitamin $\mathrm{D}$ is being synthesised, and fat mobilisation in winter, when endogenous vitamin D stores are needed, have occurred throughout much of human evolutionary history $^{(32,33)}$. Modern humans in industrialised societies typically no longer experience such seasonal variation, or other sustained periods of fat mobilisation, but pregnancy is a notable exception. During the first two trimesters of pregnancy, the mother deposits about $3.5 \mathrm{~kg}$ of fat ${ }^{(23)}$. The very high rate of mobilisation of maternal adipose tissue stores that occurs in the last trimester has the effect of making available to the placenta, and ultimately to the fetus; a significant proportion of the nutrients stored in maternal adipose tissue ${ }^{(23)}$ during the developmental period when $\mathrm{Ca}$ deposition in the fetal skeleton is maximal and vitamin D needs are greatest ${ }^{(21)}$. The critical importance of maternal stores extends through to lactation as the vitamin D status of the infant appears to be more influenced by the vitamin D status of the mother during pregnancy than by maternal vitamin $\mathrm{D}$ status during lactation when mobilisation continues ${ }^{(34)}$. Such mechanisms have helped humans to reproduce successfully at high latitude while coping with the lottery of the particular sequence of seasons experienced in each pregnancy. Mobilisation in late pregnancy of maternal vitamin $\mathrm{D}$ stores accumulated over extended periods, and possibly more than one summer, could also ameliorate the effect of a diet chronically poor in vitamin D. It may also provide a biological basis for possible additional public health measures to augment the current strategy of supplementation.

Promoting safe sun exposure and access to green space in summer has the potential to have a significant impact on vitamin D status in pregnancy, even in the north of Scotland. Such a policy could also have wider health benefits as populations that are exposed to the greenest environments also experience the lowest levels of health inequality related to deprivation ${ }^{(35)}$. We propose that a trial of safe sun advice in the critical summer months at high latitude be carried out to assess the impact on the vitamin D status of the mother during pregnancy and lactation, and the newborn and neonate in pregnancies commencing in different seasons.

We excluded non-white subjects from much of the analysis as the numbers were too small to draw any meaningful conclusions. However, it should be noted that plasma $25(\mathrm{OH}) \mathrm{D}$ in non-Caucasians was significantly lower in the maternal and cord blood and the likelihood is that all of the above considerations will be exacerbated in women with darker skin and poorer UV absorption, where the need for improved vitamin $\mathrm{D}$ status is greater.

\section{Acknowledgements}

This study was funded by the Scottish Government Health Directorate. This original sample collection was funded by the UK Food Standards Agency (grant no. N05040). P. H., G. H. and G. McN. received support from the Scottish Government Rural and Environment Research and Analysis Directorate. We thank Dr Fiona Bisset from the Scottish Government who encouraged this analysis and arranged funding. All authors contributed to the preparation of the manuscript. P. H., D. M. C. and G. McN. designed the study. D. M. C. was responsible for the collection of pregnancy information. G. H. contributed to the collection of dietary and supplement information and the collection and preparation of samples for the analysis. A. M. W., S. K. and E. B. carried out the plasma vitamin D analysis. P. H. and G. W. H. carried out the statistical analysis. The authors declare that they have no conflict of interest in relation to this work.

\section{References}

1. Committee on Medical Aspects of Food and Nutrition Policy (1991) Dietary Reference Values for Food Energy and Nutritnets for the United Kingdom. Report no. 41. London: The Stationery Office.

2. Committee on Medical Aspects of Food and Nutrition Policy (1998) Nutrition and Bone Health: With Particular Reference to Calcium and Vitamin D. Report no. 49. London: The Stationery Office.

3. Scientific Advisory Committee on Nutrition (2007) Update on Vitamin D. London: TSO.

4. Hollis BW \& Wagner CL (2004) Vitamin D requirements during lactation: high-dose maternal supplementation as therapy to prevent hypovitaminosis D for both the mother and the nursing infant. Am J Clin Nutr 80, Suppl. 6, 1752S-1758S.

5. Hypponen E \& Boucher BJ (2010) Avoidance of vitamin D deficiency in pregnancy in the United Kingdom: the case for a unified approach in National policy. Br J Nutr 104, 309-314.

6. National Institute for Health and Clinical Excellence (2008) Improving the Nutrition of Pregnant and Breastfeeding Mothers and Children in Low-income Households. Report no. 11. London: National Institute for Health and Clinical Excellence.

7. Institute of Medicince (2011) Dietary Reference Intakes for Calcium and Vitamin D. Washington, DC: The National Academic Press.

8. Hypponen E, Berry D, Cortina-Borja M, et al. (2010) 25-Hydroxyvitamin D and pre-clinical alterations in inflammatory and hemostatic markers: a cross sectional analysis in the 1958 British Birth Cohort. PLoS One 5, e10801.

9. Macdonald HM, Mavroeidi A, Fraser WD, et al. (2011) Sunlight and dietary contributions to the seasonal vitamin D status of cohorts of healthy postmenopausal women living at northerly latitudes: a major cause for concern? Osteoporos Int 22, 2461-2472 
10. Henderson L, Irving K, Gregory J, et al. (2003) The National Diet \& Nutrition Survey: Adults Aged 19 to 64 Years. Vitamin and Mineral Intake and Urinary Analytes. Report No. Vol 3. London: TSO.

11. Ruston D, Hoare J, Henderson L, et al. (2003) The National Diet \& Nutrition Survey: Adults Aged 19 to 64 Years. Nutritional Status (Anthropometry and Blood Analytes), Blood Pressure and Physical Activity. Report No. Vol 4. London: TSO.

12. Haggarty P, Campbell DM, Duthie S, et al. (2009) Diet and deprivation in pregnancy. Br J Nutr 102, 1487-1497.

13. Knox S, Harris J, Calton L, et al. (2009) A simple automated solid-phase extraction procedure for measurement of 25-hydroxyvitamin $\mathrm{D}_{3}$ and $\mathrm{D}_{2}$ by liquid chromatographytandem mass spectrometry. Ann Clin Biochem 46, 226-230.

14. Masson LF, McNeill G, Tomany JO, et al. (2003) Statistical approaches for assessing the relative validity of a foodfrequency questionnaire: use of correlation coefficients and the kappa statistic. Public Health Nutr 6, 313-321.

15. Campbell D, Hall M, Lemon J, et al. (1993) Clinical birthweight standards for a total population in the 1980s. Br J Obstet Gynaecol 100, 436-445.

16. Scottish Executive Statistics (2007) SIMD: Scottish Index of Multiple Deprivation. http://www.scotland.gov.uk/Topics/ Statistics/SIMD/Publications

17. Javaid MK, Crozier SR, Harvey NC, et al. (2006) Maternal vitamin D status during pregnancy and childhood bone mass at age 9 years: a longitudinal study. Lancet $\mathbf{3 6 7}$, $36-43$.

18. Ardawi MS, Nasrat HA \& BA'Aqueel HS (1997) Calciumregulating hormones and parathyroid hormone-related peptide in normal human pregnancy and postpartum: a longitudinal study. Eur J Endocrinol 137, 402-409.

19. Ritchie LD, Fung EB, Halloran BP, et al. (1998) A longitudinal study of calcium homeostasis during human pregnancy and lactation and after resumption of menses. Am J Clin Nutr 67, 693-701.

20. Cross NA, Hillman LS, Allen SH, et al. (1995) Calcium homeostasis and bone metabolism during pregnancy, lactation, and postweaning: a longitudinal study. Am J Clin Nutr 61, 514-523.

21. Mulligan ML, Felton SK, Riek AE, et al. (2010) Implications of vitamin D deficiency in pregnancy and lactation. Am J Obstet Gynecol 202, 429 .
22. Holmes VA, Barnes MS, Alexander HD, et al. (2009) Vitamin $\mathrm{D}$ deficiency and insufficiency in pregnant women: a longitudinal study. Br J Nutr 102, 876-881.

23. Haggarty P (2010) Fatty acid supply to the human fetus. Annu Rev Nutr 30, 237-255.

24. Cockburn F, Belton NR, Purvis RJ, et al. (1980) Maternal vitamin $\mathrm{D}$ intake and mineral metabolism in mothers and their newborn infants. Br Med J 281, 11-14.

25. Ashwell M, Stone EM, Stolte H, et al. (2010) UK Food Standards Agency Workshop Report: an investigation of the relative contributions of diet and sunlight to vitamin D status. Br J Nutr 104, 603-611.

26. Thornton A (2009) Public Attitudes and Behaviours Towards the Environment: A Report to the Department for Environment, Food and Rural Affairs. London: TNS.

27. Fraser DR (1983) The physiological economy of vitamin D Lancet 322, 969-972.

28. Haddad JG, Matsuoka LY, Hollis BW, et al. (1993) Human plasma transport of vitamin $\mathrm{D}$ after its endogenous synthesis. J Clin Invest 91, 2552-2555.

29. Wortsman J, Matsuoka LY, Chen TC, et al. (2000) Decreased bioavailability of vitamin D in obesity. Am J Clin Nutr $\mathbf{7 2}$, 690-693.

30. Tzotzas T, Papadopoulou FG, Tziomalos K, et al. (2010) Rising serum 25-hydroxy-vitamin D levels after weight loss in obese women correlate with improvement in insulin resistance. J Clin Endocrinol Metab 95, 4251-4257.

31. Zittermann A, Frisch S, Berthold HK, et al. (2009) Vitamin D supplementation enhances the beneficial effects of weight loss on cardiovascular disease risk markers. Am J Clin Nutr 89, 1321-1327.

32. Prentice AM, Hennig BJ \& Fulford AJ (2008) Evolutionary origins of the obesity epidemic: natural selection of thrifty genes or genetic drift following predation release? Int J Obes (Lond) 32, 1607-1610.

33. Wells JC (2006) The evolution of human fatness and susceptibility to obesity: an ethological approach. Biol Rev Camb Philos Soc 81, 183-205.

34. Specker BL (1994) Do North American women need supplemental vitamin D during pregnancy or lactation? Am J Clin Nutr 59, 2 Suppl., 484S-490S.

35. Mitchell R \& Popham F (2008) Effect of exposure to natural environment on health inequalities: an observational population study. Lancet 372, 1655-1660. 